\section{Time and money}

L.J.F.(Jo) Hermans, Leiden University, The Netherlands

$\mathcal{R}^{\text {ack in } 1905 \text {, when Einstein was working on relativity in which }}$ $B$ 'time' plays such an important role, he would have never guessed that time would be measured with such an astonishing accuracy just a century later. As an example, think of GPS satellite clocks: to enable us to navigate with accuracies on the order of meters, their clocks have to be precise within nanoseconds. And in laboratories around the globe, laser-cooled Cesium and Rubidium fountain clocks reach an incredible fractional accuracy of about $6 \times 10^{-16}$. This translates into errors no larger than $20 \mathrm{~ns}$ in one year (which contains almost exactly $\pi \times 10^{7}$ seconds).

But also in everyday life, things have changed dramatically. Most of us remember the prequartz era, when clocks rarely agreed to within a few minutes, and watches had to be adjusted every two days or so. Indeed, one had to resort to the radio if one wanted to know the exact time. By contrast, modern quartz clocks and watches routinely have accuracies better than 1 in $10^{6}$ : some 30 seconds in a year. And, except for the switch-over to daylight saving time, adjustment is rarely necessary.

At what cost, in terms of $\mathrm{kWh}$ and Euros, do we read our daily time so accurately? The electrical energy consumption, even for an analog clock operating on $230 \mathrm{~V}$ in our home, is very small of course, as we can tell from the negligible amount of heat released. The electrical power for such a clock is typically on the order of $1 \mathrm{~W}$, and since a year has about $10^{4}$ hours, it consumes about 10 $\mathrm{kWh}$ per year. In terms of money, that's about a Euro per year.

Now let us look at our digital watch. It typically operates on a silver oxide battery of $1.55 \mathrm{~V}$ having a charge of roughly $25 \mathrm{mAh}$. If we assume that the battery runs for at least two years, a back-ofthe-envelope calculation shows that the watch operates on a power of less than 2 microwatt. That is very little indeed: it is six orders of magnitude more efficient than an analog clock connected to the mains.

What about the cost? Such batteries cost, typYOU ARE Now lo and behold: isn't that what 23 MKRO-SECONDS the analog counterpart in our LATE I home would cost?

The conclusion is simple. Digital watches are very accurate and extremely efficient. But the energy in their battery is extremely expensive, of the order of 50000 Euros/ $\mathrm{kWh}$.

And whatever type of clock we use for knowing the time as accurately as we do, the cost is 1 Euro at most for an entire year. If Einstein were alive today, he would probably agree: that's a lot of time for very little money. 